\title{
DIAGNÓSTICO TECNOLÓGICO DE PRODUÇÃO DA CAPRINOVINOCULTURA NO MUNICÍPIO DE TAUÁ - CE
}

Technological profile of caprinovinoculture production in the municipality of Tauá $C E$

Diagnóstico tecnológico de producción de la caprinovinocultura en el municipio de Tauá - CE

Hellen Christina de Almeida Kato ${ }^{1}$, Ernandes Barbosa Belchior ${ }^{1}$, Diego Neves de Sousa*2, Octávio Rossi de Morais ${ }^{1}$

${ }^{1}$ Embrapa Pesca e Aquicultura, Palmas-TO, Brasil.

${ }^{2}$ Programa de Pós-graduação Doutorado em Desenvolvimento Rural, Universidade Federal do Rio Grande do Sul, Porto Alegre - RS, Brasil.

*Correspondência: Centro Interdisciplinar em Sociedade, Ambiente e Desenvolvimento (CISADE) - Campus Centro - Av.João Pessoa, $311^{\circ}$ andar, Porto Alegre/RS - CEP: 90040000 e-mail diegocoop@ hotmail.com

\section{RESUMO}

O Este artigo tem como objetivo descrever o manejo e as tecnologias de produção adotadas pela Embrapa no município de Tauá - CE, que receberá a unidade piloto de desenvolvimento da ovinocultura de corte do Programa Rota do Cordeiro. Para isto, realizou-se a aplicação de questionários estruturados em 336 propriedades rurais, abordando problemas de forma quantitativa. Estatísticas descritivas foram usadas na análise dos dados, com o uso do pacote estatístico SPSS, em especial o cálculo de médias e frequências. Foi possível identificar que a maioria dos entrevistados possui uma boa estrutura nas instalações, incluindo área de manejo, cochos, saleiros, bebedores e balanças. Entre a ferramenta disponível para anotações zootécnicas muitos responderam que utiliza cadernos, ficha específica e computador. Conclui-se que as práticas de manejo e escrituração zootécnica são incipientes nos rebanhos do município, mesmo que existentes em algum nível dentro das propriedades.

Palavras-chave: Instalações, técnicas agropecuárias, ovinos.

\begin{abstract}
This article aims to describe the handling and production technologies adopted in the municipality of Tauá - CE, to receive the cutting sheep industry development of pilot plant Program Cordeiro Route. For this, there was the application of structured questionnaires in 336 rural properties, addressing problems quantitatively. Descriptive statistics were used to analyze the data using the SPSS statistical package, in particular the calculation of means and frequencies. It was identified that the majority of respondents have a good structure on the premises, including management area, troughs, salt shakers, drinkers and scales. Among the available tool for animal husbandry notes many responded that uses notebooks, record specific and computer. It is concluded that the practices of management and bookkeeping zootecnica are incipient in the herds of the municipality, even if they exist at some level within the properties.
\end{abstract}

Keywords: Installations, Agronomical techniques, Ovine.

\section{RESUMEN}

Este artículo tiene como objetivo describir el manejo y las tecnologías de producción adoptadas por la Embrapa en el municipio de Tauá - CE, que recibirá la unidad piloto de desarrollo de la ovinocultura de corte del Programa Ruta del Cordero. Para ello, se realizaron la aplicación de cuestionarios estructurados en 336 propiedades rurales, abordando problemas de forma cuantitativa. Las estadísticas descriptivas se utilizaron en el análisis de los datos, con el uso del paquete estadístico SPSS, en especial el cálculo de medias y frecuencias. Es posible identificar que la mayoría de los encuestados posee una buena estructura en las instalaciones, incluyendo área de manejo, cochos, salones, bebedores y balanzas. Entre la herramienta disponible para anotaciones zootécnicas muchos respondieron 
que utiliza cuadernos, ficha específica y computadora. Se concluye que las prácticas de manejo y escritura zootécnica son incipientes en los rebaños del municipio, aunque existen en algún nivel dentro de las propiedades.

Descriptores: instalaciones, técnicas agropecuarias, ovinos.

\section{INTRODUÇÃO}

O Nordeste sempre se destacou na produção de ovinos e caprinos, sendo que o rebanho caprino, segundo dados do IBGE (2014), responde por 91,6\% do nacional. Bahia foi o Estado brasileiro como maior efetivo (26,7,\%), seguido pelos estados de Pernambuco $(23,6 \%)$, Piauí $(13,9 \%)$ e Ceará $(11,7 \%)$. Ainda segundo dados do IBGE (2014), o crescimento dos rebanhos de 2013 para 2014 foi de 0,8\%. Já o quantitativo de ovino concentrado na região Nordeste é de $57,5 \%$ do efetivo nacional que obteve um crescimento de $1,9 \%$ em relação ao obtido no ano de 2013.

A ovinocultura é uma atividade de significativa relevância social para a agropecuária brasileira, constituindo-se como uma importante fonte geradora de emprego e renda, além de contribuir para a oferta de alimentos e produtos de valor econômico em regiões áridas, semiáridas e montanhosas, sendo assim, uma alternativa de aproveitamento de terras pouco agricultáveis (Batista e Souza, 2015).

Belchior et al. (2014) ressaltam a importância econômica, social e ambiental da caprinovinocultura explorada no semiárido nordestino. Embora considerem que a criação de ovinos na região é caracterizada por apresentar baixo nível tecnológico, pouco produtiva e carência de acompanhamento técnico especializado e gerenciamento produtivo, condições similares à maioria das pequenas propriedades agrícolas presentes no Nordeste brasileiro. Em estudo conduzido com produtores de ovinos no município cearense de Tauá ${ }^{1}$, estes mesmos

\footnotetext{
${ }^{1}$ De acordo com Belchior et al. (2014), Tauá-CE possuía o terceiro maior rebanho de ovinos e o segundo maior número de estabelecimentos rurais em produção de ovinos da região Nordeste.
}

autores afirmam que a produção de ovinos está concentrada em pequenas propriedades, onde os animais são criados de forma extensiva e a vegetação de caatinga figura como principal suporte alimentar dos rebanhos. O quadro traçado por aqueles autores demonstra que os criadores de caprinos e ovinos, além dos aspectos produtivos, demandam políticas públicas distintas e coordenadas que perpassam estratégias que vão desde transferência de renda, aquisição de alimentos, desenvolvimento econômico, eletrificação rural, crédito agrícola e acesso à água potável.

Santos-Cruz e Almeida (2014), por sua vez, ressaltam que o mercado para a carne ovina e caprina está aquecido e não se restringe apenas aos consumidores regionais/tradicionais. Segundo os autores, esses produtos têm boa aceitação nas redes de supermercado, frigoríficos, feiras livres e restaurantes de nível elevado, localizados principalmente em grandes centros do País.

Considerando esta potencial demanda, o Ministério da Integração Nacional (MI) ${ }^{2}$ propôs um programa de desenvolvimento da ovinocultura de corte, denominado Rota do Cordeiro ${ }^{3}$. O Programa tem como objetivo a implantação de núcleos de inovação na produção de ovinos de corte, em localidades com produção tradicional e concentração de rebanhos em diferentes estados do Nordeste, criando um ambiente que favoreça a demonstração e utilização de tecnologias que podem melhorar a renda do produtor de ovinos de corte, facilitar o acesso ao mercado formal e incentivar o associativismo, bem como disponibilizar

\footnotetext{
${ }^{2}$ A fusão entre o Ministério da Integração Nacional e o Ministério das Cidades, em 01 de janeiro de 2019, deu origem ao Ministério do Desenvolvimento Regional.

${ }^{3}$ Mais informações sobre o Programa Rota do Cordeiro ver em Homma et al. (2018).
} 
material genético melhorado, com base no próprio rebanho local.

Como sede do projeto piloto do Programa, foi escolhido o município de Tauá, na mesorregião dos Inhamuns, estado do Ceará, por já possuir alguma organização entre produtores, beneficiamento e comércio tradicionais de caprinos e ovinos, envolvendo o produto "manta de carneiro", além de sua proximidade física com a Embrapa Caprinos e Ovinos (CNPC). Além disso, características edafo-climáticas da Região dos Inhamuns Cearense são favoráveis à produção, sendo Tauá o $12^{\circ}$ município com o maior rebanho ovino no país e o maior no estado do Ceará com 137.345 cabeças (IBGE, 2012).

Assim, este trabalho tem como objetivo descrever o manejo e as ferramentas para produção adotadas pela Embrapa no município de Tauá - CE, que receberá a unidade piloto de desenvolvimento da ovinocultura de corte do Programa Rota do Cordeiro (Ministério da Integração). Assim, buscou analisar as tecnologias adotadas correntemente pelos produtores da região, que servirão como base para futuras avaliações de impacto, além de ferramenta para a identificação das demandas tecnológicas e fornecimento de elementos para a formulação de políticas públicas visando à reversão das ameaças e aproveitamento das oportunidades para a produção de ovinos.

\section{MATERIAIS E MÉTODOS}

Tendo como base a classificação de Richardson (2007) para pesquisas em ciências sociais, este trabalho caracteriza-se por ser uma pesquisa descritiva de abordagem quantitativa. Foram realizadas coletas de dados a campo, através de 336 entrevistas realizadas com produtores aleatórios, ligados à criação de ovinos de corte, exclusivamente ou não, proprietários de terras dentro dos limites do município de Tauá - CE.

O questionário foi elaborado pela equipe de pesquisadores do CNPC, contemplando as diversas expertises, definindo-se questões consideradas importantes para efeito de caracterização de propriedades. A partir desta definição elaborou-se um questionário constando de três partes. A parte I corresponde à caracterização socioeconômica da produção; a parte II refere-se à produção em si e tecnologias empregadas e a parte III traz informações sobre os meios de comercialização dos ovinos produzidos.

No presente artigo serão caracterizadas as instalações, ferramentas e quais as tecnologias de manejo já adotadas por estes produtores, referentes à segunda parte do questionário aplicado.

Para validação do questionário, foi realizado no município de Tauá um Workshop de dois dias (16 horas) com a presença dos 20 aplicadores, selecionados entre técnicos e extensionistas rurais da região, com experiência na aplicação de pesquisas, no qual se pôde realizar um pré-teste nas quais várias perguntas foram readequadas à realidade da região, com a simplificação de alguns questionamentos ou inclusão/exclusão de variáveis analíticas.

$\mathrm{Na}$ oportunidade, foi realizado um treinamento e pré-teste de aplicação dos questionários com produtores presentes, sendo o tempo de aplicação estimado entre 1,5 a 2 horas por produtor.

Os 20 aplicadores foram distribuídos em quatro equipes de cinco entrevistadores, sendo um deles coordenador e responsável pela aplicação dos questionários e estas equipes foram divididas seguindo uma rota para cobertura dos diversos distritos do município. Foi realizado em dez dias de aplicação de questionários em dois turnos. 
A definição do tamanho amostral (336 questionários) foi feita levando em consideração o rebanho e o número de produtores. Para isso, foram efetuados os cálculos preconizados por Triola (2011) em que:

Onde:

$$
\mathrm{n}=\frac{\mathrm{Z}^{2} \cdot \alpha / 2 \mathrm{pq}}{\mathrm{E}^{2}}
$$

$\mathrm{n}$ = Número de indivíduos na amostra

$\mathrm{Z}^{2} \alpha / 2=$ Valor crítico que corresponde ao grau de confiança desejado.

$\mathrm{p}=$ Proporção populacional de indivíduos que pertence à categoria que estamos interessados em estudar $\mathrm{q}$ = Proporção populacional de indivíduos que não pertence à categoria que estamos interessados em estudar $(\mathrm{q}=1-\mathrm{p})$

$\mathrm{E}=$ Margem de erro ou erro máximo de estimativa. Identifica a liderança máxima entre proporção amostral e a verdadeira proporção populacional (p).

Para a escolha das propriedades participantes da pesquisa utilizou-se o cadastro de produtores rurais, fornecido pela Secretaria Municipal de Agricultura do município, sendo selecionados aleatoriamente produtores nas rotas de distritos visitados por cada equipe ao longo dos dias de aplicação, possibilitando uma cobertura ampla do território do município.

Os produtores foram entrevistados em suas residências e/ou locais de trabalho. Alguns produtores não sabiam ou não controlavam as informações sobre determinadas questões. Nestes casos, a questão foi considerada como não respondida.

Os dados foram tabulados no software SPSS$21 \circledR$, sendo gerados os quadros de distribuição de frequências para as variáveis analisadas.

\section{RESULTADOS E DISCUSSÃO}

Sobre as instalações utilizadas para a criação dos ovinos, $171(57,6 \%)$ apontaram possuir currais (também denominados chiqueiros) e 52 (17,5\%) possuíam aprisco. Apenas quatro dos entrevistados $(1,3 \%)$ afirmaram não possuir instalação na propriedade. As estruturas presentes nestas instalações estão descritas na Tabela 1.

Tabela 1. Estruturas presentes nas instalações que abrigam o rebanho ovino nas propriedades entrevistadas

\begin{tabular}{lcccc}
\hline \multicolumn{1}{c}{ Estrutura } & Possui & Não Possui & Sem resposta & Total \\
\hline Área de manejo & $202(60,5 \%)$ & $132(39,5 \%)$ & 2 & $336(100,0 \%)$ \\
\hline Cochos & $239(71,1 \%)$ & $97(28,9 \%)$ & - & $336(100,0 \%)$ \\
\hline Saleiros & $245(72,9 \%)$ & $91(27,1 \%)$ & - & $336(100,0 \%)$ \\
\hline Bebedouros & $126(37,5 \%)$ & $210(62,5 \%)$ & - & $336(100,0 \%)$ \\
\hline Balança & $97(28,9 \%)$ & $239(71,1)$ & - & $336(100,0 \%)$ \\
\hline
\end{tabular}

Fonte: Dados elaborados pelos autores.

Sobre a higiene das instalações, 325 produtores $(98,5 \%)$ afirmaram limpar os currais com frequência, sendo que os principais destinos para o esterco recolhido são às plantações domésticas (240/76,4\%) e doações feitas para outras propriedades
(31/9,9\%). Em relação às carcaças dos animais encontrados mortos na propriedade, 118 produtores $(35,1 \%)$ queimaram-nas enquanto $164 \quad(48,8 \%)$ depositaram-nas em terrenos baldios ou à beira da estrada. Esses resultados diferem daqueles observado 
por Cardoso et al. (2015), que ao caracterizarem a ovinocultura no estado de São Paulo constataram que a limpeza dos apriscos se dá de forma mensal - sendo as fezes destinadas às esterqueiras, fora do alcance dos animais - e que as carcaças dos animais mortos são enterradas na própria propriedade

Em relação aos utensílios para manejo dos animais presentes nas propriedades, destacam-se: pistola dosificadora $(152 / 53,1 \%)$; tesoura para casqueamento $(39 / 13,6 \%)$ e Alicate Burdizzo para castração $(12 / 4,2 \%)$. Enquanto $25,5 \%$ dos produtores (73) afirmaram não possuir qualquer utensílio para auxílio no manejo dos animais.

A importância das instalações dentro de um processo de produção é facilitar o manejo, reduzindo os custos das tarefas diárias, melhorar o acompanhamento do rebanho no controle de doenças, proteção e segurança aos animais, armazenamento de alimentos, favorecendo, assim, maior eficiência produtiva.

Deve-se levar em consideração a realidade local, ao inferir que o uso de tecnologias depende também de sua devida adaptação, para o aproveitamento pleno de suas vantagens nas instalações apropriadas.

Quanto a ocorrência de procedimentos para a identificação dos animais, $271(83,1 \%)$ produtores afirmaram realizar algum tipo procedimento. Os cortes na orelha ainda são o principal e o mais fácil tipo de identificação utilizado pelos produtores, conforme demonstra a Tabela 2. Esses resultados contrastam com aqueles observados por Cardoso et al. (2015) em que $80 \%$ dos criadores de ovinos no estado de São Paulo não fazem nenhum tipo de identificação em seus animais.

\footnotetext{
4279 produtores responderam à questão, sendo possível mais de uma resposta por produtor. As porcentagens registradas referemse à ocorrência de um procedimento dentre o universo dos produtores que apresentaram resposta válida
}

Tabela 2. Tipo de identificação utilizada na propriedade ${ }^{4}$

\begin{tabular}{lcc} 
Procedimento & Frequência & Percentual \\
\hline Brinco & 60 & $21,5 \%$ \\
\hline Tatuagem & 34 & $12,2 \%$ \\
\hline Colar/Corda & 11 & $3,9 \%$ \\
\hline Medalha & 1 & $0,4 \%$ \\
\hline Corte na orelha & 188 & $67,4 \%$ \\
\hline Ferra & 37 & $13,3 \%$ \\
\hline Outros & 6 & $2,2 \%$ \\
\hline Total & $337 *$ & $120,8 \% * *$ \\
\hline
\end{tabular}

Fonte: Dados elaborados pelos autores

Para 211 produtores $(78,7 \%)$, o procedimento de identificação dos animais deve ocorrer, principalmente, por ocasião da desmama, oportunidade em que já se realizam manejos com o animal, facilitando o processo. Enquanto $52(19,4 \%)$ assinalam que fazem após o nascimento dos animais. Quanto à realização de escrituração zootécnica, apenas 66 produtores $(19,6 \%)$ informaram realizar algum tipo de anotação (Tabela 3).

Tabela 3. Anotações zootécnicas realizadas pelos produtores $^{5}$

\begin{tabular}{lcc}
\multicolumn{1}{c}{ Registro } & Frequência & Percentual \\
\hline Nascimentos & 58 & $85,3 \%$ \\
\hline Coberturas & 21 & $30,9 \%$ \\
\hline Mortes & 18 & $26,5 \%$ \\
\hline Medicamentos & 13 & $19,1 \%$ \\
\hline Vermifugações & 31 & $45,6 \%$ \\
\hline Vacinações & 43 & $63,2 \%$ \\
\hline Pesagens & 7 & $10,3 \%$ \\
\hline Compras & 12 & $17,6 \%$ \\
\hline Vendas & 25 & $36,8 \%$ \\
\hline Mão-de-obra & 4 & $5,9 \%$ \\
\hline Outros & 3 & $4,4 \%$ \\
\hline Total & $235^{*}$ & $345,6 \% * *$ \\
\hline Fon &
\end{tabular}

Fonte: Dados elaborados pelos autores.

\footnotetext{
5 *65 Produtores responderam à questão, sendo possível mais de uma resposta por produtor.

**As porcentagens registradas referem-se à ocorrência de um procedimento dentre o universo dos produtores que apresentaram resposta válida.
} 
Quanto à forma de escrituração, 46 produtores $(68,6 \%)$ utilizaram o caderno/caderneta para realizar as anotações. Quatro produtores $(6,0 \%)$ fizeram o uso de fichas específicas para este fim e apenas um $(1,5 \%)$ utilizou o computador.

Em relação às técnicas de castração dos animais, 209 produtores $(62,4 \%)$ afirmaram realizar algum tipo de procedimento, em que o uso do alicate do tipo Burdizzo é o mais comum (Tabela 4).

Tabela 4. Técnicas utilizadas para castração de cordeiros ${ }^{6}$

\begin{tabular}{lcc}
\multicolumn{1}{c}{ Técnica } & Frequência & Percentual \\
\hline Alicate tipo Burdizzo & 181 & $86,6 \%$ \\
\hline Cirúrgico (bisturi) & 1 & $0,5 \%$ \\
\hline $\begin{array}{l}\text { Cirúrgico } \\
\text { (faca/canivete) }\end{array}$ & 3 & $1,4 \%$ \\
\hline Elastrador & 9 & $4,3 \%$ \\
\hline Outros & 15 & $7,2 \%$ \\
\hline Total válido & 209 & $100,0 \%$ \\
\hline Sem resposta & 127 & - \\
\hline Total & 336 & $100,0 \%$ \\
\hline
\end{tabular}

Fonte: Dados elaborados pelos autores.

Ainda sobre o processo de castração dos animais, 128 produtores $(51,3 \%)$ afirmaram que o período de castração se dá entre 3 a 6 meses de idade, sendo que este procedimento, na maioria das vezes $(71,4 \%)$ é realizado pelo próprio produtor; $17,5 \%$ por parentes, vizinhos ou amigos e 4,4\% dos casos, por um profissional técnico qualificado. Ribeiro et al. (2003) consideram que a castração de ovinos é uma prática recomendada para facilitar o manejo do rebanho e enquanto estratégia para abate em animais de idade mais avançadas. Outra técnica de manejo que teve seu emprego investigado foi a desmama. Dos produtores entrevistados, $222(67,9 \%)$ responderam que não realizam qualquer procedimento para desmama dos animais. Em relação àqueles que realizaram algum procedimento, as idades mencionadas como adequadas para a desmama foram:
90 dias $(34 / 36,6 \%) ; 120$ dias $(18 / 19,4 \%)$ e 60 dias $(12 / 12,9 \%)$. Entre as técnicas mais utilizadas para as desmamas dos cordeiros, a separação das crias é a mais utilizada (Tabela 5).

Tabela 5. Técnicas utilizadas para a desmama de cordeiros

\begin{tabular}{lcc}
\multicolumn{1}{c}{ Técnica } & Frequência & Percentual \\
\hline $\begin{array}{l}\text { Apenas separa as } \\
\text { crias }\end{array}$ & 58 & $62,4 \%$ \\
\hline $\begin{array}{l}\text { Realiza manejo de } \\
\text { mamada e "secagem } \\
\text { das matrizes" }\end{array}$ & 9 & $9,7 \%$ \\
\hline $\begin{array}{l}\text { Separa as crias e } \\
\text { altera a alimentação } \\
\text { da matriz }\end{array}$ & 17 & $18,3 \%$ \\
\hline Outros procedimentos & 9 & $9,7 \%$ \\
\hline Total válido & 93 & $100,0 \%$ \\
\hline Sem resposta & 13 & - \\
\hline Total & 105 & $100,0 \%$ \\
\hline
\end{tabular}

Fonte: Dados elaborados pelos autores.

Ainda em relação ao processo de desmama, apenas $8(7,62 \%)$ realizaram a pesagem dos cordeiros e $4(3,81 \%)$ a pesagem das matrizes no momento da desmama.

Em relação ao casqueamento dos animais, 37 produtores (11,2\%) informaram realizar esse procedimento, sendo que desse total, $48,4 \%$ adotaramno duas vezes ao ano e 35,5\% uma vez ao ano, principalmente no período chuvoso da região (janeiromaio). O casqueamento é um dos principais procedimentos para se evitar doenças e lesões podais (Embrapa, 2007).

Silveira et al. (2016) informam que negligenciar uma técnica como essa, de fácil procedimento, acarreta sérias perdas aos produtores rurais em função das lesões ocasionadas que reduzem a mobilidade dos animais, causa desconforto, 
desvalorização das carcaças, perdas nos índices produtivos e descarte dos animais.

A engorda de cordeiros após a desmama foi uma estratégia adotada por 127 produtores $(38,3 \%)$, dos quais $98(77,2 \%)$ realizaram algum tipo de seleção para a inclusão destes animais no período de engorda. Já a engorda de animais adultos, antes do período de venda, foi feita por 81 produtores $(57,4 \%)$. Ter uma estratégia de alimentação para engorda dos animais é indispensável, principalmente tratando-se quando a suplementação se dá de forma extensiva, como é a predominância na maioria dos produtores rurais da região Nordeste do Brasil (Seganfredo, 2007).

Porto et al. (2013), ao caracterizarem o sistema de produção em um município de Jussara-BA, constataram - diferentemente do observado no município de Tauá-CE, em que a alimentação dos rebanhos se dá exclusivamente pelo sistema extensivo -, que os produtores têm conhecimento da importância de suplementar os animais em períodos críticos de escassez alimentar, ainda que haja um custo para aquisição dos concentrados, mas que é diluído aos custos de produção em função da valorização do quilo da carne ovina em épocas de maior demanda.

\section{CONCLUSÃO}

Os dados da pesquisa demonstram que práticas de manejo e escrituração zootécnica são incipientes nos rebanhos do município de Tauá, mesmo que existentes em algum nível dentro das propriedades, o que demonstra um ambiente propício para intervenções sociotécnicas e ações de transferência de conhecimentos visando a adoções de tecnologias simples que geram impactos a curto e médio prazo, aumentando a produtividade nas propriedades do município e, consequentemente, gerando maior renda para o produtor.
Todos os autores declararam não haver qualquer potencial conflito de interesses referente a este artigo.

\section{REFERÊNCIAS}

BELCHIOR, E. B.; SOUZA, J. D. F.; ALMEIDA, H. C. G.; MORAIS, O. R.; SHIOTSUKI, L. A Importância do perfil socioeconômico de criadores de ovinos de corte na elaboração de políticas públicas. In: CONGRESSO DA SOCIEDADE BRASILEIRA DE ECONOMIA, ADMINISTRAÇÃO E SOCIOLOGIA RURAL, 52, 2014, Goiânia. Anais...Goiânia: SOBER, p.1-17., 2014.

CARDOSO, M.V.; PINO, F.A.; FEDERSONI, I.S.P.; LUCCHESE FILHO, A.; FELICIO, A.L. Caracterização da Caprinocultura e Ovinocultura o estado de São Paulo. Arquivos Instituto Biologia, São Paulo, v.82, p. 1-15, 2015

EMBRAPA. Criação de caprinos e ovinos. Embrapa Informação Tecnológica, Brasília, DF. 2007.

HOMMA, A. K. O; NOVO, A. L. M; UDRY, M. C. F. V; NOGUEIRA, J. D; MORAIS, O.; CAMARGO, A. C; HOLANDA JUNIOR, E. V; OLIVEIRA, F. N. S. Tecnologias da Embrapa no contexto da redução das desigualdades e geração de renda. In: DIAS, T. A. B; UDRY, M. C. F. V; HEBERLÊ, A. L. O; NOGUEIRA, J. D. (Eds). Redução das desigualdades: Contribuições da Embrapa para os Objetivos de Desenvolvimento Sustentável. $1^{\text {a }}$ ed.Brasília/DF: Embrapa, 2018.

IBGE. Produção pecuária municipal 2014. Rio de Janeiro, v. 42, p. 1-39, 2014.

PORTO, L.L.M .A.; SALUM, W.B.; ALVES, C. Caracterização da Ovinocaprinocultura de corte na região do centro norte baiano. Revista Brasileira de Gestão e Desenvolvimento Regional, v.9, n.1, p.281296, 2013.

RICHARDSON, R. J. Pesquisa social: Métodos e técnicas. $3^{\text {a }}$ ed., São Paulo: Atlas, 2007.

SANTOS-CRUZ, C. L.; ALMEIDA, H. C. G. Agroindústria e processamento da carne ovina. In: A. B. SELAIVE-VILARROEL; J. C. S. OSÓRIO. (Orgs.). Produção de ovinos no Brasil. $1^{a}$ ed., São Paulo: Roca, v. 1, p. 501-524, 2014.

RIBEIRO, E.L.A.; SILVA, L.D.F.; ROCHA, M.A.; MIZUBUTI, Y.Y. Desempenho de cordeiros inteiros ou submetidos a diferentes métodos de castração 
abatidos aos $30 \mathrm{~kg}$ de peso vivo. Revista Brasileira de Zootecnia, v.32, n. 3, p. 745-752

SEGANFREDO, M. A. Gestão ambiental na Suinocultura. Brasília: Embrapa Informação Tecnológica, 2007. 302p.

SILVEIRA, C.S.; DAMBORIARENA, P.A.; MORAIS, R.M.; TROST, M.E.; POZZOBON, R.; ANJOS, B.L. Lesões podais em ovinos da Mesorregião Sudoeste do Rio Grande do Sul.
Pesquisa Veterinária Brasileira, v. 36, n.10, p.971978, 2016.

TRIOLA, M. F. Introdução à estatística. $10^{\mathrm{a}}$ ed., Rio de janeiro: LTC, 2011.

BATISTA, N. L.; SOUZA, B. B. Caprinovinocultura no semiárido brasileiro - fatores limitantes e ações de mitigação. ACSA - Agropecuária Científica no Semiárido, v.11, n 2, p 01-09, 2015. 